where $F$ denotes the mechanical force between two coils when each carries the same current $I, M$ denotes the mutual inductance between the coils, and the $z$-axis is the direction of the force. This law has been established with the highest precision for the special case of the current balance built of non-magnetic material, the force $F$ being determined by weighing, in terms of mass, and the quantity $\frac{d M}{d z}$ by application of the law of mutual inductance in terms of the geometrical property $\frac{d N}{d z}$. I can be measured fundamentally over a limited range, and thus the dynamometer law is established by means of the current balance in the form

$$
m g=a I^{2} \mu_{0} \frac{d N}{d z} .
$$

The proportionality constant $a$, unlike $\mu_{0}$ in the previous law, appears to be characteristic of no important property. We therefore choose our unit of $I$ so that $a$ takes the value of unity and disappears from our working equation, which becomes

$$
F=I^{2} \frac{d M}{d z} \text {. }
$$

Next in the sequence is Ohm's Law, the law of the potentiometer, which can be established in the form

$$
E=b I . R,
$$

since both $E$ and $R$ can be measured fundamentally, while $I$ can be measured both fundamentally and by means of the dynamometer law. The constant $b$ appears to be characteristic of no important property and is therefore suppressed by a suitable choice of units for $E$ and $R$.

It is impossible to pursue the subject further here, but the examples given are suficient to show the kinds of law that form our real foundations at the present time. These foundations change to some extent with changing technique. The basic laws are those of the instruments and operations which have enabled us to correlate our experiences with the highest precision, and have therefore been used in establishing our working standards. At the present time, alternating currents are employed for precision electrical work to an increasing extent, and therefore some of the laws concerning alternating currents are of basic importance. Note that the electrodynamometer law provides us with a means of measuring alternating current as well as direct current, and then by means of the electrostatic voltmeter we can extend Ohm's Law to certain classes of conductors, namely, resistors. Thus we can define and measure alternating potential difference. Faraday's Law of Induction can then be established in the form in which it states the relation between the alternating potential difference at the secondary terminals of a mutual inductor $M$ of which the primary carries a current $I$. Adopting the usual vector notation, we establish the law

$$
E=k M \omega I,
$$

and then choose the unit of $E$ so that $k=1$. The constant $b$ which appeared in Ohm's Law is then suppressed by a suitable choice of the unit of resistance.

It is unfortunate that this system of laws, upon which our experimental work is based, does not readily link up to form a simple logical development of the theory of the subject; but once we have recognized the great difference between the basic experimental laws and the theoretical relations which have been devised as the simplest easily workable system consistent with these laws, we are prepared to find differences of opinion as to which theoretical scheme can be used with the least risk of confusion.

\section{PSYCHOLOGICAL ASPECTS OF MORAL PROGRESS}

A WIDESPREAD readiness to re-examine human A values makes it particularly appropriate at the present time to ask whether recent scientific work can add to our understanding of moral advance. This was the question taken up in a discussion on "Psychological Aspects of Moral and Social Progress" at a meeting of the British Psychological Society on September 23, in which the chief speakers were Prof. J. C. Flugel, Prof. Karl Mannheim and Dr. R. H. Thouless.

In opening the discussion, Prof. Flugel suggested that, as a first approximation, we may identify eight mental tendencies exhibited in what we regard as moral progress. Once recognized, they can be illustrated in three fields of comparison: they differentiate the mind of the infant and child from the more mature mind, the abnormal (pathological) mind from the healthy mind, and the primitive from the civilized culture. These eight tendencies may be briefly stated.

(1) There is a trend away from ego-centricity and towards sociality, an increasing readiness to subordinate one's own immediate requirements to the needs of one's fellows, and to find satisfaction in the well-being of groups ever more broadly conceived, so that what starts as a concern for a few family associates may develop into loyalty to a nation, a church, or the whole human race. Among the psychological mechanisms involved in this process, an important part is played by vicarious satisfaction; our interest goes out to people very different from ourselves because they represent some of what William James called the 'potential selves' which we all give up in becoming our own one self.

(2) Progress towards greater consciousness, away from the control of conduct and feeling by unconscious urges, also appears in the advance towards individual maturity and civilized social organization. Progress along this line is pre-eminently the aim of psycho-analysis. At the same time, it must be recognized that, conscious scrutiny having thoroughly performed its task, much behaviour has to be releg. ated to the habitual and the automatic. Individual conscious life is supported by a mass of habits, reflexes, and other non-conscious determining tendencies. In social life, traditions and conventions have a similar role. Their value lies in the economy they effect, their danger in that they may grow antiquated and ill-adapted; but they must always be necessary in mental and social organization, simply because the span of consciousness at any one time is strictly limited.

(3) The trend towards realistic thinking, away from dreaming and 'wishful thinking' in individual life, and away from magic in social life, is a third mark of advance. Science, Freud has suggested, is essen- 
tially an endeavour to think according to the 'reality principle'.

(4) Social and individual progress shows a gradual replacement of aggression by tolerance. Primitive and infantile mortality is marked by a sweeping aggressiveness which gives place in later development, to finer discriminations and broader tolerance. The mature mind can better tolerate unwelcome stimuli, including new points of view, and has less need to react in aggressive defence of things as they are. In one respect this appears as the toleration of criticism which is vital to science; in another as that capacity for 'collaboration in opposition' which Madariaga has noted particularly in the British national character.

(5) A trend is to be seen in individual and social advance towards spontaneity in doing what is regarded as right, in contrast to the more primitive reliance on strong prohibitions against 'wrong' impulses after they have arisen. In the child's development, the external prohibitions are replaced by the internal control of the super-ego, and with increasing maturity the conflict grows less between the superego and the impulses it controls. One aim of psychoanalysis is to replace the crude inhibitory power of the super-ego by the ego's more delicate discrimination. So, too, right behaviour among primitive groups depends more on taboos and the avoidance of sins, but in civilized societies more upon the sublimation of impulses into permissible channels.

(6) A progressively greater freedom from irrational anxieties is seen in the child's development and in the advance from primitive to civilized societies, superstitions and phobias being shed, bogies of all kinds less and less remembered. In psycho-analysis the patient's progress exemplifies the same trend.

(7) As development proceeds, the individual shows increasing self-responsibility. In controlling his behaviour he judges with greater autonomy, and is less at the mercy of the ready-made morality of the group or the super-ego. The same tendency is seen socially in the advance from generalized taboo to reliance on individual conscience; and, politically, towards democracy instead of submission to a dictator.

(8) The eighth developmental trend shows moral judgments increasingly penetrated by intellectual understanding. The cognitive approach to what we disapprove of begins to displace the mainly affective and conative procedures of condemnation and attack. In reply to discussion on this point, Prof. Flugel made it clear that a moral judgment must always remain, and action must be taken against what we condemn; but with increased maturity the means adopted will be chosen in the light of much fuller intellectual understanding. The handling of delinquents illustrates the point : the modern effort to investigate, to view separately the sin and the sinner, is an advance beyond the simple condemnation and punishment which, considering that they have been practised for some millennia, have achieved relatively little.

Prof. Flugel suggested these eight tendencies only as a first approximation, and he later inclined to agree with Dr. Thouless that a ninth should be added-the tendency towards greater voluntary control of action, the passage from uncontrolled to controlled behaviour. While adding this ninth tendency, however, Dr. Thouless was emphatic that he could not regard such tendencies as aspects of 'progress'. He viewed them as a description in psychological terms of the criteria by which we distinguish between the better and the worse in conduct. That the better does in fact come later in the life-history of the individual and the social group is a separate question, to be decided only by an examination of the facts of child psychology and of anthropology. The term 'moral progress' implies an answer to this question, which may or may not be true. He doubted, for example, whether the tendency towards sociality and away from ego-centricity is greater in civilized than in primitive groups.

Prof. Mannheim, reading the first paper in comment upon Prof. Flugel's thesis, had already given critical attention to the concept of 'progress'. Speaking as a sociologist--and welcoming a discussion that brought both psychology and his own science to bear on the problem-he pointed out that the notion of progress grew up in the nineteenth century, an era of industrialization and economic expansion. Impressed by the seemingly endless possibilities of material advance, thinkers of the time carried over the same optimistic attitude into their view of the human mind. But this confidence in social and moral advance as an inherent feature of the historical process has been deeply shaken by the political and international events of the twentieth century.

In Prof. Mannheim's view, society shows no inevitable cultural development through recognizable stages. Such a phenomenon as Germany's return to the tribal mind and over-socialization is not to be termed a 'regression', for the trend in the opposite direction is not a normal or natural process. To suppose that it should be, is to blind ourselves to the more important moulding of behaviour by environmental conditions. For a detailed understanding of a group at any period our chief need is, not to know what point it has reached on a linear scale of progress, but to relate its current mental attitudes to its concrete environment, social and technical.

As an example, Prof. Mannheim pointed out that an industrial society, appearing late in the historical sequence, may nevertheless produce through its uniform repetitive tasks and its social institutions which reduce the opportunity for individual choicefar less individualized personalities than an earlier society without mass production. It depends on the particular organization of society whether the trader, for example, grows acutely aware of the difference between his own interests and the interests of others, as he did under laisser-faire, or whether he thinks rather in terms of collective action by a group of associated merchants or a guild of craftsmen.

As a member of our contemporary culture, Prof. Mannheim is ready to agree that he, too, values the eight tendencies which Prof. Flugel identified. But as a sociologist he challenges the frame of reference within which the psychologist makes his judgments.

Dr. Thouless, in his comment on Prof. Flugel's paper, not only objected to the suggestion that the eight tendencies represent 'progress', but also doubted whether they are all aspects of any single process or at all closely related with one another. For example, one might go far towards realistic thinking (3) without becoming any less aggressive (4). Rather than assume a unified stream of progress we should do better to recognize that there are many ways in which men and societies can improve.

Like Prof. Mannheim, Dr. Thouless stressed the limitations of moral judgments made within our contemporary frame of reference. Thus our own readiness to talk as if aggressiveness were the principal evil may seem to later observers as relative and 
peculiar a characteristic as the nineteenth century's readiness to regard sexual indulgence as the chief of sins. Again, the sense of guilt has gone through cultural vicissitudes. Puritanism made it a moral good in itself. Psycho-analytic writers now speak as if it were merely pathological. But it has a valid function to perform: it can serve to deter us from a repetition of those acts which we ourselves condemn. In fact, in Dr. Thouless's opinion, the modern tendency to belittle the idea of sin goes too far. The fact of $\sin$ (whether we take a religious view of it or not) occurs whenever a man's voluntarily controlled behaviour falls short of his own accepted standards. Even in these modern times, we retain a vivid sense of sin when others commit it; nowadays a man is prone to repent of his neighbour's sin and to apply the light of scientific understanding to his own.

In general, Dr. Thouless believes that the psychoanalytic approach represented by Prof. Flugel's eight principles suffers from an intellectual bias. It describes moral betterment as if that were primarily a matter of getting better principles and moral ideas, and seems to neglect the problem of bringing actual behaviour into line with those moral principles. For this reason he proposed the ninth tendency already referred to - a progressive increase in the voluntary control of conduct. But, as he was careful to point out, this trend by itself does not ensure an improvement in conduct, since voluntary effort may be directed towards wrong ends. The ethical questions remain.

The meeting was left to decide whether, as Dr. Thouless suggested, the effort to discuss the nature of right and wrong in the new technical language of psycho-analysis is primarily a test of the adequacy of that language ; or whether, as Prof. Flugel holds, certain psycho-analytic conceptions, such as that of the super-ego, actually throw new light on moral problems.

\section{OBITUARIES}

\section{Prof. Gustav Gilson}

News comes from Belgium that M. Gustav Gilson, embryologist at Louvain, fisheries expert at Ostend, died last winter. He was eighty-two years old, and though he kept busy to the end the best of his work was done well-nigh sixty years ago.

Gilson was Carnoy's favourite pupil : when Carnoy started his famous journal, La Cellule, Gilson figured as co-editor, and the first number contained his "Etude comparée [or part of it] de la Spermatogénèse des Arthropodes". The next was by Carnoy himself, "Sur la cytodiérèse chez les Arthropodes", in other words, on mitotic cell-division. It was a great enterprise to start this costly journal in a small university like Louvain; but natural science was no new thing in that University. It was there that Theodor Schwann wrote his "Observations microscopiques", and laid the foundations of the cell-theory. P. J. van Beneden had been professor there for forty years, and his "Ostéographie des Cétacés" was famous. His son Edouard was a leading embryologist of F. M. Balfour's time, and had just published a paper which became classical, on the egg of Ascaris megalocephala but he left Louvain for Liège (as Schwann also had done), and Louvain and Liège seldom saw eye to eye. Other papers of Gilson's, more or less important at the time, were for example on "Les glandes odorifères de Blaps mortisaga" (1886); a whole series on "La soie et les appareils séricigènes" (1890-94) ; and a careful histological study of "Les cellules musculo-glanduleuses de l'Owenia", a genus of Annelides (1898). When Carnoy died all too soon in 1899 Gilson pronounced the customary Eloge, and did it with grace and tenderness: he carried on La Cellule as sole editor until it came to an end, like much else in Louvain, during the War of 1914-18.

Gilson carried on the Department of Zoology well and efficiently, but did little more histological or embryological work after Carnoy's death. He had a family connexion with Ostend, and the latter years of his life were spent there; he began to interest himself in the local fisheries, and in course of time established a Fisheries Laboratory, and even issued a journal (Annales de l'Institut) in connexion with it. $\mathrm{He}$ was not one of the founders of the Conseil International, but he took part in our second meeting in Copenhagen (1903), and attended regularly thereafter. One of the first of his fishery publications was on the reproduction and migrations of the eel, a burning question at the time; another, about 1910, was an elaborate statistical study of the great plaice-fishery ; yet another, and an interesting one, was on the 'Guai', or winter-herring of the Belgian coast. Other fishery papers mostly dealt with the busy fleet of motor and sailing cutters, trawling and shrimping off the Belgian coast, and landing, or still worse destroying, prodigious quantities of 'undersized' fish. A report which he made to the Council in 1928 was the completest account of such a fishery that had ever been drawn up, and the many million of small fish destroyed made a startling story.

Gustav Gilson married late in life, but very happily. $\mathrm{He}$ was reticent of speech, austere of manner, of grave and intellectual countenance; during fifty years acquaintance I found him a faithful friend, a real scholar and a true man.

D'Arcy W. Thompson.

\section{Mr. H. Tetley}

Mr. H. Tetrey, curator in zoology at the Bristol Museum and Art Gallery, died on September 26 at the relatively early age of fifty-four. Educated at Malvern College and graduating B.Sc. in the University of Leeds in 1916, he carried out postgraduate research in entomology in the University of Manchester. During the War of 1914-18 he served as a paymaster in the R.N.V.R. and on demobilization was appointed assistant demonstrator in zoology and curator of the zoological museum in the University of She field.

After a serious illness - the effects of which really undermined his health for life-Tetley was appointed in 1927 to take charge of the Zoological Department of the Bristol Museum and Art Gallery. There he overhauled the extensive collections, prepared and arranged new exhibits, and instituted the organization of records concerning the local distribution and occurrence of many groups of animals. It was a severe blow to him when in 1940 many of these records and much of the collections were destroyed by enemy action. He was especially conversant with local birds and mammals, and his publications reflect these interests. Many of these papers were published in the Proceedings of the Bristol Naturalists' Society, and by far his most important work was an 